\title{
Neuropatologia da cinomose canina: 70 casos $(2005-2008)^{1}$
}

\author{
Marcia C. Silva ${ }^{2}$, Rafael A. Fighera ${ }^{3}$, Alexandre Mazzanti ${ }^{4}$, Juliana S. Brum², \\ Felipe Pierezan ${ }^{2}$ e Claudio S.L. Barros ${ }^{3}$
}

\begin{abstract}
Silva M.C., Fighera R.A., Mazzanti A., Brum J.S., Pierezan F. \& Barros C.S.L. 2009 [Neuropathology of canine distemper: 70 cases (2005-2008).] Neuropatologia da cinomose canina: 70 casos (2005-2008). Pesquisa Veterinária Brasileira 29(8):643-652. Departamento de Patologia, Universidade Federal de Santa Maria, 97105-900 Santa Maria, RS, Brazil. E-mail: mctogni@yahoo.com.br

The current study was performed to determine the pathology and distribution of lesions in the central nervous system (CNS) of 70 dogs naturally affected by canine distemper. Cases were grouped according to the age of the dogs and classified according to the evolution of the lesions. It was possibly to conclude that: (1) the encephalomyelitis induced by canine distemper virus is more prevalent in puppies and adults; (2) gross lesions in the CNS occur infrequently; (3) the brain is more frequently affected than the spinal cord; (4) the five anatomical sites of the rain more frequently affected are, in decreasing order of frequency, cerebellum, diencephalon, frontal lobe of telencephalon, pons and mesencephalon; (5) the anatomical site more frequently affected in the spinal cord is the cervical (C1-C5) segment; (6) subacute and chronic lesions are more common than acute ones; (7) demyelization is the more prevalent lesion and occur mainly in the cerebellum, pons and diencephalons, usually associated with astrogliosis and nonsuppurative inflammation; (8) in most cases with astrogliosis, gemistocytic astrocytes are observed, frequently with syncitia formation; (9) non-suppurative leptomeningitis, malacia and cortical neuronal necrosis are moderately frequent in the brain and less so in the spinal cord; (10) inclusion bodies are frequent in the brain; occur mainly in astrocytes and less frequently in neurons, however independently of the affected cell they occur mainly in the nucleus; (11) a classification of canine distemper encephalitis based in age-related clinical syndromes it is not accurate.
\end{abstract}

INDEX TERMS: Diseases of dogs, neuropathology, canine distemper.

RESUMO.- Este estudo teve como objetivo realizar uma investigação anátomo-patológica detalhada das lesões e sua distribuição no sistema nervoso central (SNC) de cães com cinomose. Foram avaliadas secções padronizadas do encéfalo e da medula espinhal de 70 cães. Os casos

\footnotetext{
${ }^{1}$ Recebido em 14 de abril de 2009.

Aceito para publicação em 30 de abril de 2009.

Parte da tese de doutorado do primeiro autor.

2 Programa de Pós-Graduação em Medicina Veterinária, área de concentração em Patologia Veterinária, Centro de Ciências Rurais (CCR), Universidade Federal de Santa Maria (UFSM), Camobi, Santa Maria, RS 97105-900, Brasil. *Autor para correspondência: mctogni@yahoo.com.br

${ }^{3}$ Departamento de Patologia, Centro de Ciências da Saúde, UFSM, Santa Maria, RS.

${ }^{4}$ Departamento de Clínica de Pequenos Animais, CCR, UFSM, Santa Maria, RS.
}

foram agrupados de acordo com a idade dos cães e classificados conforme a evolução das lesões. Os resultados permitem concluir que: (1) encefalomielite induzida pelo vírus da cinomose canina é mais prevalente em filhotes e adultos; (2) lesões macroscópicas no SNC ocorrem com baixa freqüência; (3) o encéfalo é mais acometido do que a medula espinhal; (4) as cinco regiões anatômicas mais afetadas do encéfalo são, em ordem decrescente de freqüência, o cerebelo, o diencéfalo, o lobo frontal, a ponte e o mesencéfalo; (5) a região anatômica mais afetada da medula espinhal é o segmento cervical cranial (C1-C5); (6) lesões subagudas e crônicas são mais comuns do que lesões agudas; (7) desmielinização é a lesão mais prevalente e ocorre principalmente no cerebelo, na ponte e no diencéfalo, quase sempre acompanhada de astrogliose e inflamação não-supurativa; (8) na maior parte dos casos em que há astrogliose, observam-se astrócitos 
gemistocíticos, freqüentemente com formação de sincícios; (9) leptomeningite não-supurativa, malacia e necrose cortical laminar são lesões relativamente freqüentes no encéfalo, mas não na medula espinhal; (10) corpúsculos de inclusão no encéfalo são muito comuns, ocorrem principalmente em astrócitos e com freqüência menor em neurônios; no entanto, independentemente da célula afetada, são vistos predominantemente no núcleo; (11) uma classificação da encefalite na cinomose com base em síndromes clínicas relacionadas com a idade do cão é imprecisa.

TERMOS DE INDEXAÇÃO: Doenças de cães, neuropatologia, cinomose canina.

\section{INTRODUÇÃO}

Cinomose é uma doença viral altamente contagiosa causada pelo vírus da cinomose canina (VCC), um Morbillivirus da família Paramyxoviridae (Fenner 2004). Além de cães, cinomose afeta várias outras espécies de carnívoros (Appel \& Summers 1995), entretanto, o cão representa o principal reservatório para o vírus da cinomose e serve como fonte de infecção para carnívoros selvagens (Moll et al. 1995). A cinomose acomete cães de qualquer idade, raça e sexo (Chrisman 1985, Tipold et al. 1992, Thomas et al. 1993), mas tem maior predileção por filhotes (Gillespie 1962, Appel 1969, Krakowka \& Koestner 1976) e indivíduos não-vacinados (Chappuis 1995). Os cães infectados pelo VCC desenvolvem sinais clínicos e lesões respiratórias, gastrintestinais, dermatológicas, oftalmológicas e neurológicas, que podem ocorrer seqüencialmente, simultaneamente ou isoladamente (Greene \& Appel 2006).

Pesquisas sobre cinomose, abrangendo aspectos como etiologia, epidemiologia, patogenia, patologia, imunologia e técnicas de diagnóstico são realizadas há mais de dois séculos, entretanto, estudos neuro-histopatológicos completos da cinomose são escassos e antigos, pois foram realizados principalmente nas décadas de 1940 e 1950 (Perdrau \& Pugh 1930, Hurst et al. 1943, Maclntyre et al. 1948, Innes 1949, Koprowski et al. 1950, Trevan 1952, Ribelin 1953, Lauder et al. 1954, Gillespie \& Rickard 1956). Estudos neuro-histopatológicos recentes são ainda mais incomuns (Koutinas et al. 2002, Gebara et al. 2004, Amude et al. 2006). Vários neuropatologistas têm compilado os resultados de alguns desses estudos e os publicaram como parte de capítulos de livros (Innes \& Saunders 1962, Chrisman 1985, Summers et al. 1995, Caswell \& Williams 2007, Maxie \& Youssef 2007,). Mesmo assim, com certa freqüência, estudos neuro-histopatológicos sobre cinomose apresentam limitações, como: (1) ausência do exame da medula espinhal (Gillespie \& Rickard 1956, Gebara et al. 2004), (2) pequeno número de fragmentos examinados, geralmente incluindo apenas o cerebelo ou o cerebelo e o córtex telencefálico (Koprowski et al. 1950, Gillespie \& Rickard 1956, Gebara et al. 2004), (3) falta de especificação das regiões anatômicas do sistema nervoso central (SNC) estudadas
(Maclntyre et al. 1948) e (4) pequeno número de cães utilizados, que varia entre quatro (Hurst et al. 1943) e 50 (Lauder et al. 1954), mas geralmente não excede 20 indivíduos (Koprowski et al. 1950, Gillespie \& Rickard 1956, Koutinas et al. 2002, Amude et al. 2006).

Um estudo recente, conduzido no Laboratório de Patologia Veterinária (LPV) da Universidade Federal de Santa Maria (UFSM) (Fighera et al. 2008), demonstrou que encefalite por cinomose representa a principal causa de morte ou razão para eutanásia de cães necropsiados na Mesorregião do Centro Ocidental Rio-Grandense. Em razão disso, foi realizado nesse laboratório um estudo retrospectivo com base em 620 casos neurológicos de cinomose (Silva et al. 2007). Esse estudo utilizou cães necropsiados no LPV-UFSM entre 1965-2006 e seus resultados revelaram várias limitações, o que ensejou um segundo estudo, dessa vez prospectivo, realizado com 70 cães com cinomose necropsiados nesse mesmo laboratório, pertencentes a essa mesma mesorregião e conduzido entre 2006-2008. O objetivo desse estudo foi realizar uma investigação anátomo-patológica detalhada das lesões e de sua distribuição no SNC de cães com cinomose, a fim de auxiliar patologistas veterinários no diagnóstico dessa importante doença.

\section{MATERIAL E MÉTODOS}

Secções padronizadas do encéfalo $(n=70)$ e da medula espinhal $(n=54)$ de cães com cinomose foram processadas rotineiramente para a preparação de lâminas histológicas coradas com hematoxilina e eosina (HE) a fim de descrever a distribuição, freqüência e evolução das lesões. Essas secções incluíam: (1) lobo frontal (ao nível do joelho do corpo caloso [incluindo os núcleos basais]); (2) lobo parietal; (3) lobo temporal; (4) hipocampo; (5) lobo piriforme; (6) diencéfalo; (7) lobo occipital; (8) mesencéfalo (na altura dos colículos rostrais); (9) ponte (com pedúnculos cerebelares); e (10) cerebelo. Excetuando-se o cerebelo, a ponte e o mesencéfalo, as demais secções do encéfalo foram avaliadas unilateralmente. A medula espinhal foi dividida em quatro regiões: cervical cranial (C1-C5), cervicotorácica (C6-T2), toracolombar (T3-L3) e lombossacra (L4-S3). A região cervical cranial compreendia os segmentos cervicais craniais e médios; a região cervicotorácica incluía os segmentos cervicais caudais e os torácicos craniais; a região toracolombar compreendia os segmentos torácicos médiocaudais e os lombares craniais e a região lombossacra representava os segmentos lombares caudais e os segmentos sacrais. Três secções de cada região da medula espinhal foram examinadas histologicamente em cada caso.

As lesões foram classificadas em agudas, subagudas ou crônicas com base em critérios previamente estabelecidos, foram eles: apenas desmielinização (lesão aguda), desmielinização acompanhada de inflamação leve a moderada (lesão subaguda) e desmielinização acompanhada de inflamação moderada a acentuada e malacia (lesão crônica) (Vandevelde et al. 1985, Tipold et al. 1992).

O método de inclusão dos casos neste estudo foi a presença de lesões histológicas no SNC características da infecção pelo VCC acompanhadas de inclusões virais (corpúsculos de Lentz) observadas na microscopia de luz em secções coradas com HE. Não foram incluídos casos com diagnóstico clínico de 
encefalite por cinomose em que havia co-infecções ou em que não foi possível observar os corpúsculos de Lentz no encéfalo ou na medula espinhal, mesmo que esses corpúsculos tivessem sido observados em órgãos extra-neurais.

Os parâmetros avaliados nas diversas secções do SNC incluíram desmielinização, inflamação, malacia, necrose cortical laminar, necrose neuronal não-laminar, cromatólise, neuronofagia, perda neuronal, astrogliose, formação de sincícios, hipertrofia (tumefação) e hiperplasia endotelial, esferóides axonais e câmaras de digestão. Os corpúsculos de Lentz foram classificados quanto ao tipo celular envolvido, quanto à localização na célula (intranuclear e/ou intracitoplasmática) e quanto à distribuição no SNC. Astrocitose (hiperplasia de astrócitos) e astrogliose (aumento no número de processos fibrosos astrocitários) são termos intercambiáveis que descrevem a reação dos astrócitos em diferentes situações (Summers et al. 1995). Neste estudo o termo astrogliose será utilizado para descrever a hipertrofia e hiperplasia de astrócitos.

Os casos foram agrupados de acordo com a idade em oito categorias: cães até seis meses, cães entre sete meses e um ano, cães com um ano, cães com dois anos, cães com três e quatro, cães com cinco e seis anos, cães com sete e oito anos e cães com nove anos ou mais.

\section{RESULTADOS}

Os 70 cães com cinomose por nós estudados estavam distribuídos quanto à idade da seguinte maneira: cães com até seis meses (24/70; 34,3\%), cães entre sete meses e um ano (9/70; 12,8\%), cães com um ano (11/70; 15,7\%), cães com dois anos $(7 / 70 ; 10,0 \%)$, cães com três e quatro anos (6/70; 8,6\%), cães com cinco e seis anos (6/70; $8,6 \%)$, cães com sete e oito anos $(5 / 70 ; 7,1 \%)$ e cães com nove anos ou mais $(2 / 70 ; 2,8 \%)$.

Dos 70 encéfalos examinados, lesões macroscópicas foram observadas em cinco $(7,1 \%)$ casos e correspondiam à dilatação moderada dos ventrículos laterais (4/70; $5,7 \%)$ e amolecimento com depressão da substância branca telencefálica subcortical dos lobos frontal e occipital (1/ $70 ; 1,4 \%$ ). Das 54 medulas espinhais examinadas, em duas $(3,7 \%)$ havia alteração macroscópica caracterizada por amolecimento do parênquima com perda da definição do "H" medular.

Histologicamente, dos 70 encéfalos e das 54 medulas espinhais examinados, em $64(91,4 \%)$ e $36(66,7 \%)$ havia algum tipo de lesão relacionada ao VCC. A prevalência das lesões de acordo com as regiões do encéfalo, independentemente do tipo de lesão, foi a seguinte: cerebelo (64/70; $91,4 \%)$, telencéfalo $(61 / 70 ; 87,1 \%)$ e tronco encefálico (57/70; 81,4\%). A distribuição das lesões no telencéfalo foi a seguinte: lobos frontal $(53 / 70 ; 75,7 \%)$, occipital $(40 / 70 ; 57,1 \%)$, parietal $(35 / 70 ; 50,0 \%)$, temporal $(31 / 70 ; 44,3 \%)$, hipocampo $(27 / 70 ; 38,6 \%)$ e lobo piriforme (15/70; 21,4\%). A distribuição das lesões no tronco encefálico foi a seguinte: diencéfalo (55/70; 78,6\%), ponte $(51 / 70 ; 72,8 \%)$ e mesencéfalo $(49 / 70 ; 70,0 \%)$. A distribuição das lesões na medula espinhal, independentemente do tipo de lesão, foi a seguinte: segmento C1-C5 (32/54; 59,2\%), segmento L4-S3 (26/54; 48,1\%), segmento T3-L3 (24/54; 44,4\%) e segmento C6-T2 (20/54; 37,0\%).

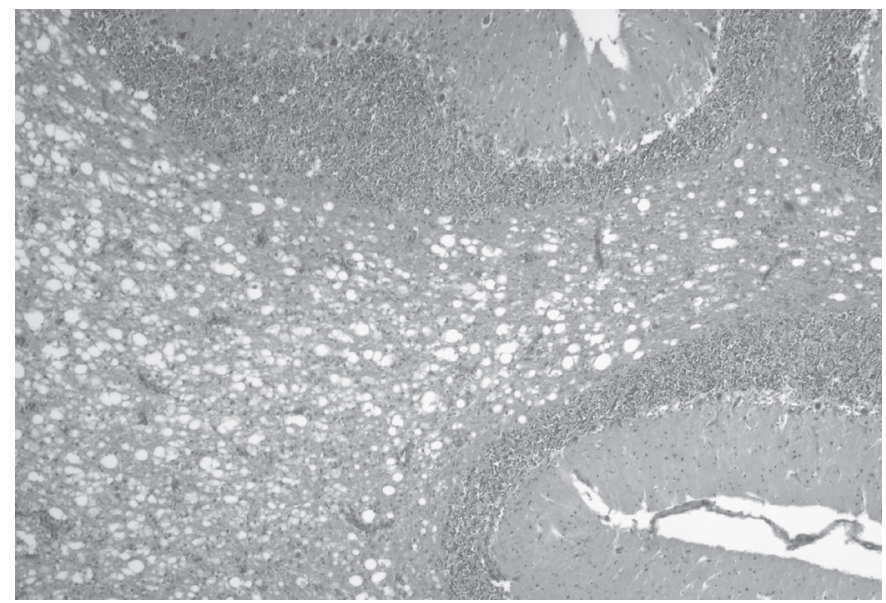

Fig.1. Desmielinização acentuada na substância branca das folhas e da medular do cerebelo. HE, obj.4x.

Comparando as lesões que ocorreram no encéfalo e na medula espinhal, desmielinização foi a lesão mais prevalente, tanto no encéfalo (64/70; 91,4\%) quanto na medula espinhal $(30 / 54 ; 55,6 \%)$. Com relação à distribuição da desmielinização no SNC, o cerebelo (Fig.1) foi afetado na maioria dos casos (62/70; 88,6\%); o tronco encefálico (54/70; $77,1 \%)$, a medula espinhal (30/54; 55,6\%) e

\section{Quadro 1. Distribuição por estrutura anatômica dos locais afetado pela desmielinização na cinomose canina}

\begin{tabular}{lcc}
\hline \multicolumn{1}{c}{ Estrutura anatômica } & $\begin{array}{c}\text { Casos com } \\
\text { desmielinização/ } \\
\text { total de casos }\end{array}$ & $\%$ \\
\hline Folhas do cerebelo & $48 / 70$ & 68,6 \\
Substância medular do cerebelo & $43 / 70$ & 61,4 \\
Teto do quarto ventrículo & $43 / 70$ & 61,4 \\
Medula espinhal (segmento C1-C5) & $25 / 54$ & 46,3 \\
Tegmento mesencefálico & $28 / 70$ & 40,0 \\
Trato óptico & $23 / 70$ & 32,8 \\
Lobo frontal & $22 / 70$ & 31,4 \\
Cápsula interna (ramo anterior) & $21 / 70$ & 30,0 \\
Lobo occipital & $21 / 70$ & 30,0 \\
Medula espinhal (segmento C6-T2) & $16 / 54$ & 29,6 \\
Medula espinhal (segmento T3-L3) & $16 / 54$ & 29,6 \\
Medula espinhal (segmento L4-S3) & $16 / 54$ & 29,6 \\
Pedúnculos cerebelares & $20 / 70$ & 28,6 \\
Pedúnculos cerebrais & $16 / 70$ & 22,8 \\
Lobo parietal & $15 / 70$ & 21,4 \\
Lobo temporal & $12 / 70$ & 17,1 \\
Cápsula interna (ramo posterior) & $12 / 70$ & 17,1 \\
Substância negra & $9 / 70$ & 12,8 \\
Assoalho do quarto ventrículo & $8 / 70$ & 11,4 \\
Quiasma óptico & $8 / 70$ & 11,4 \\
Teto mesencefálico & $4 / 70$ & 5,7 \\
Trato espinotalâmico (ponte) & $4 / 70$ & 5,7 \\
Substância branca que circunda o NGL ${ }^{a}$ & $4 / 70$ & 5,7 \\
Habênula & $3 / 70$ & 4,3 \\
Pirâmides & $3 / 70$ & 4,3 \\
Fascículo longitudinal medial (ponte) & $2 / 70$ & 2,8 \\
Fórnice hipotalâmico & $2 / 70$ & 2,8 \\
Trato tegmental central (ponte) & $2 / 70$ & 2,8 \\
Corpo trapezóide & $1 / 70$ & 1,4 \\
Lemnisco medial (ponte) & $1 / 70$ & 1,4 \\
\hline Núco genicula laterat. & & \\
\hline
\end{tabular}

a Núcleo geniculado lateral. 
o telencéfalo $(31 / 70 ; 44,3 \%)$ foram menos freqüentemente acometidos. No tronco encefálico, desmielinização ocorreu principalmente na ponte (46/70; $65,7 \%)$ e no diencéfalo (43/70; 61,4\%) e menos comumente no mesencéfalo (33/ $70 ; 47,1 \%)$. No telencéfalo, desmielinização foi mais comum no lobo frontal $(30 / 70 ; 42,9 \%)$ do que nos lobos occipital $(21 / 70 ; 30,0 \%)$, parietal $(15 / 70 ; 21,4 \%)$ e temporal (12/70; 17,1\%). Na medula espinhal, desmielinização foi mais prevalente no segmento C1-C5 (25/54; 46,3\%) do que nos segmentos C6-T2 (16/54; 29,6\%), T3-L3 (16/ $54 ; 29,6 \%)$ e L4-S3 (16/54; 29,6\%). A distribuição completa da desmielinização no SNC pode ser encontrada no Quadro 1.

Inflamação não-supurativa, caracterizada por infiltrado inflamatório linfoplasmocitário nos espaços de VirchowRobin, leptomeninges e epêndima, foi mais prevalente no encéfalo (51/70; 72,8\%) do que na medula espinhal (22/ $54 ; 40,7 \%)$. Com relação aos casos que apresentaram inflamação não-supurativa no encéfalo, encefalite não-supurativa $(49 / 70 ; 70,0 \%)$ foi mais prevalente que meningite nãosupurativa (31/70; 44,3\%) e ependimite não-supurativa (5/ $70 ; 7,1 \%)$. Em 30/70 (42,8\%) casos havia meningoencefalite não-supurativa. Com relação aos casos que apresentaram inflamação não-supurativa na medula espinhal, mielite não-supurativa $(19 / 54 ; 35,2 \%)$ foi mais prevalente que meningite não-supurativa (10/54; 18,5\%). Em 8/54 $(14,8 \%)$ casos havia meningomielite não-supurativa.

Com relação à distribuição da inflamação no parênquima encefálico, encefalite foi mais prevalente no telencéfalo $(40 / 70 ; 57,1 \%)$ do que no tronco encefálico (36/70; $51,4 \%)$ e cerebelo (31/70; $4,3 \%)$. No telencéfalo, a encefalite afetou principalmente o lobo frontal (28/70, $40,0 \%)$ e menos freqüentemente os lobos parietal (19/70; $27,1 \%)$, occipital (18/70; 25,7\%), temporal (15/70; $21,4 \%)$, hipocampo (13/70; $18,6 \%)$ e lobo piriforme $(8 / 70 ; 11,4 \%)$. No tronco encefálico, encefalite teve prevalência semeIhante no diencéfalo ( $23 / 70 ; 32,8 \%)$, no mesencéfalo (21/ $70 ; 30,0 \%)$ e na ponte (21/70; 30,0\%) (Fig. 2).

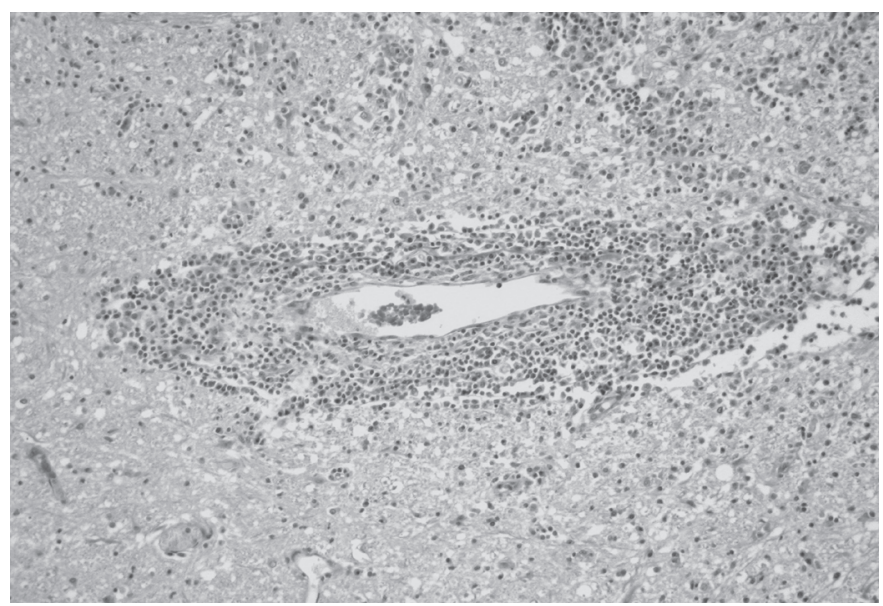

Fig.2. Encefalite linfoplasmocitária acentuada no pedúnculo cerebelar médio. Manguito perivascular formado por cerca de 15 camadas de células. HE, obj.10x.
Com relação aos casos que apresentaram meningite no encéfalo, a inflamação foi mais freqüente no tronco encefálico $(22 / 70 ; 31,4 \%)$ do que no cerebelo (13/70; $18,6 \%)$ e no telencéfalo $(12 / 70 ; 17,1 \%)$. No tronco encefálico, meningite foi vista principalmente no mesencéfalo (20/70; $28,6 \%)$ e no diencéfalo $(14 / 70 ; 20,0 \%)$ e menos freqüentemente na ponte (7/70; $10,0 \%)$. No telencéfalo, a meningite ocorreu principalmente no lobo temporal (6/70; $8,6 \%)$ e menos freqüentemente nos lobos frontal (4/70; $5,7 \%)$, occipital (4/70; $5,7 \%$ ) e parietal (2/70; $2,8 \%)$.

Ependimite foi observada no quarto ventrículo (4/70; $5,7 \%)$, ventrículos laterais ( $3 / 70 ; 4,3 \%)$ e no terceiro ventrículo $(3 / 70 ; 4,3 \%)$. Em todos os casos com ependimite no quarto ventrículo e ventrículos laterais havia sincícios de células do epêndima, vistos como células grandes, entre 50-80 $\mu \mathrm{m}$ de diâmetro, de citoplasma abundante e eosinofílico e com 2-8 núcleos (Fig.3). Em todos esses casos, em meio à proliferação de astrócitos periventriculares, foram

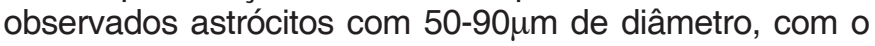
citoplasma volumoso e homogeneamente eosinofílico, contendo múltiplos núcleos dispostos na periferia da célula

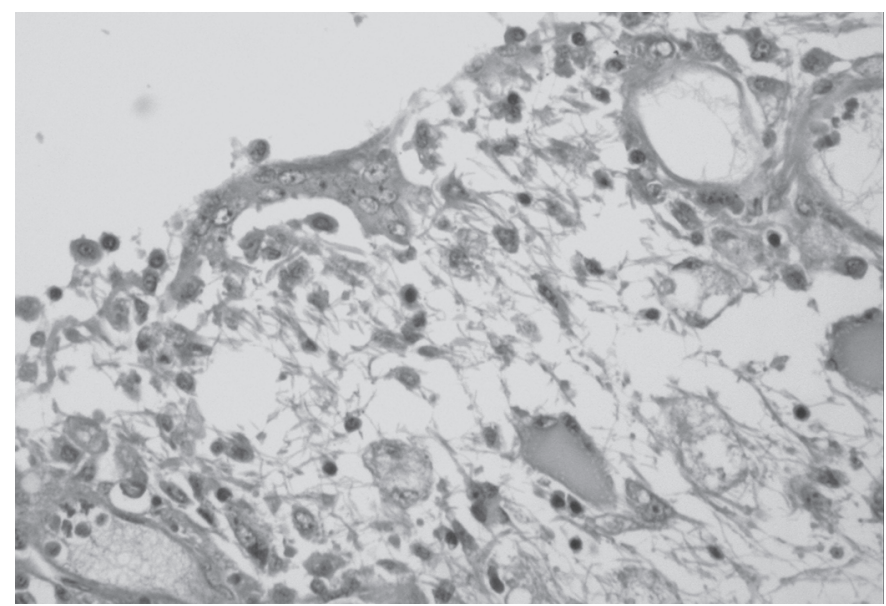

Fig.3. Sincícios de células do epêndima no assoalho do quarto ventrículo em meio à marcada desmielinização. HE, obj.20x.

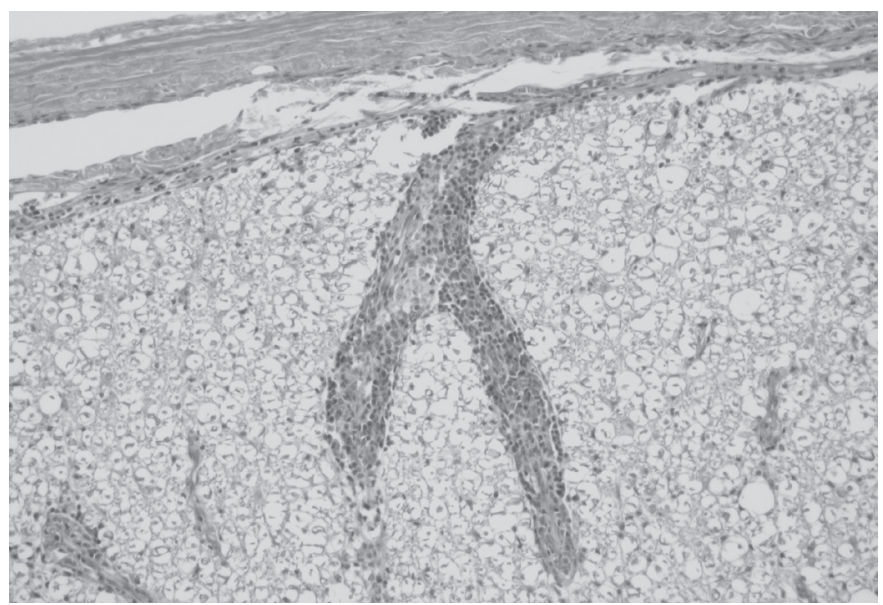

Fig.4. Leptomeningite e mielite linfoplasmocitária acentuadas no funículo dorsal da medula espinhal. HE, obj.10x. 

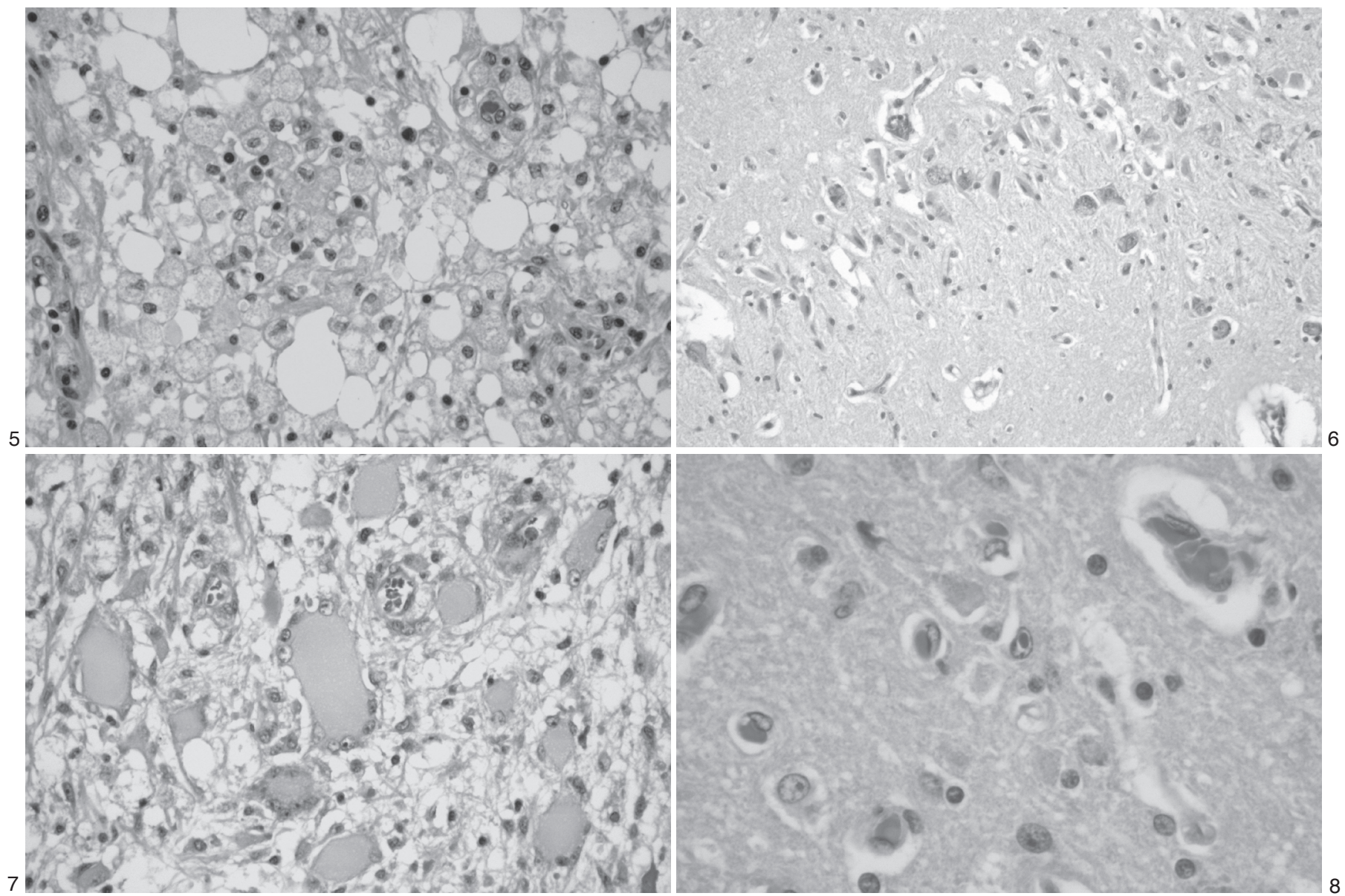

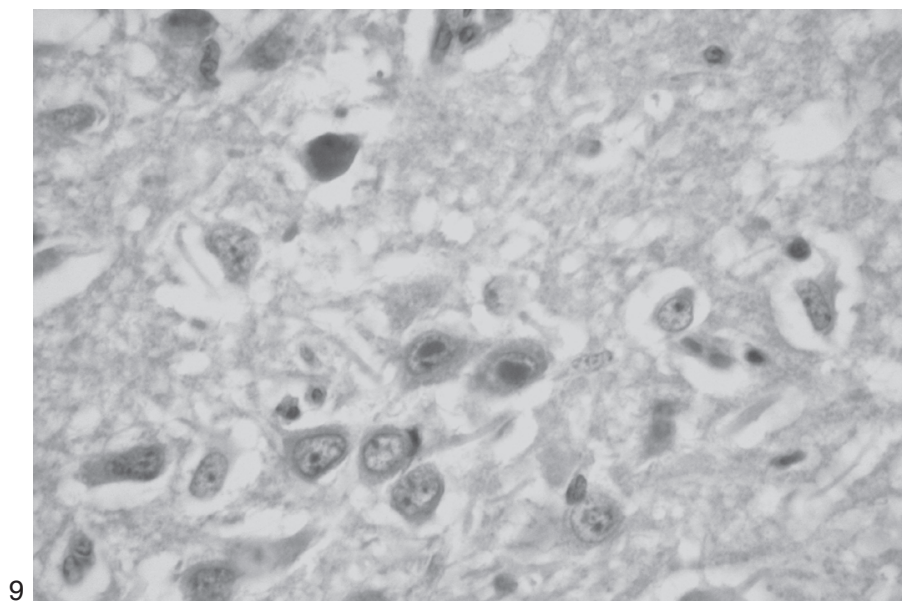

Fig.5. Malacia acentuada na substância branca da medular do cerebelo. Observam-se numerosos macrófagos com o citoplasma espumoso (células gitter), alguns deles num espaço perivascular. Há desmielinização concomitante. HE, obj.20x.

Fig.7. Numerosos gemistócitos multinucleados em meio à marcada desmielinização na substância branca medular do cerebelo. HE, obj.20x.

Fig.9. Corpúsculos de inclusão intranucleares em neurônios da camada piramidal do hipocampo. HE, obj.40x.

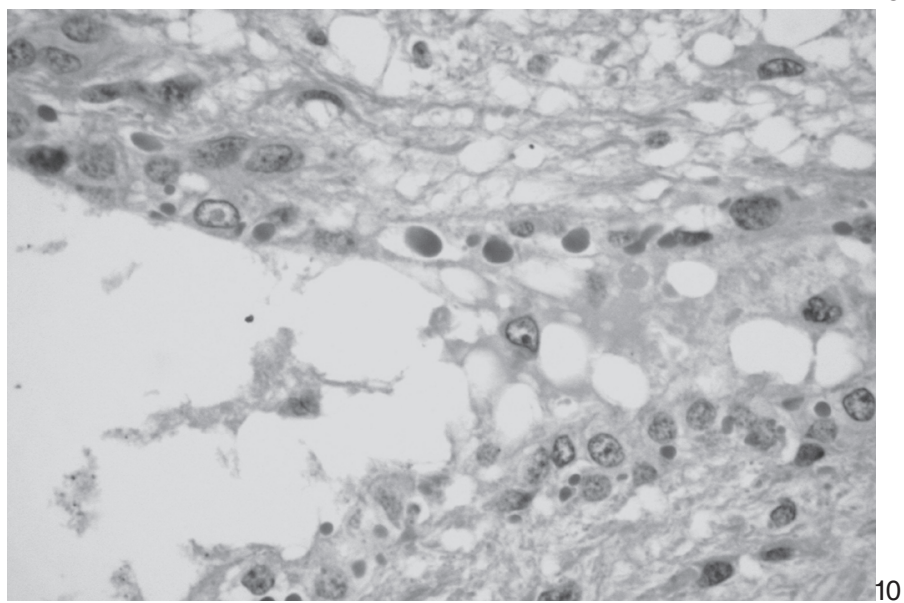

Fig.6. Necrose cortical laminar da camada piramidal do hipocampo. Alguns neurônios com aparência histológica relativamente normal aparecem entre os neurônios vermeIhos. HE, obj.20x.

Fig.8. Corpúsculo de inclusão intranuclear em um astrócito na substância cinzenta do lobo frontal. HE, obj.40x.

Fig.10. Vários corpúsculos de inclusão intracitoplasmáticos de diversos tamanhos nas células epiteliais do epêndima que reveste o quarto ventrículo. Algumas inclusões parecem estar soltas no centro de um vacúolo. Há um corpúsculo de inclusão intranuclear. HE, obj.40x. 
(gemistócitos multinucleados). A ependimite foi sempre acompanhada de desmielinização e inflamação extensa do parênquima circunjacente. Plexocoroidite linfoplasmocitária foi observada em apenas um caso $(1,4 \%)$.

Com relação à distribuição da inflamação no parênquima da medula espinhal, mielite (Fig.4) foi mais prevalente nos segmentos C1-C5 (15/54; $27,8 \%)$ e L4-S3 (13/ $54 ; 24,1 \%)$ do que nos segmentos T3-L3 (10/54; 18,5\%) e C6-T2 (8/54; $14,8 \%)$. Com relação aos casos que apresentaram meningite na medula espinhal (Fig.4), ela foi mais prevalente no segmento C1-C5 $(9 / 54 ; 16,7 \%)$ do que nos segmentos L4-S3 (4/54; 7,4\%), C6-T2 (3/54; 5,6\%) e T3-L3 (3/54; 5,6\%).

Malacia, observada como cavidades preenchidas por numerosos macrófagos com citoplasma abundante e vacuolizado e núcleo deslocado para a periferia (macrófagos espumosos ou células gitter), acompanhada de elementos vasculares, foi mais prevalente no encéfalo (22/ $70 ; 31,4 \%)$ do que na medula espinhal $(7 / 54 ; 13,0 \%)$. Em $2 / 70(2,8 \%)$ casos havia mieloencefalomalacia. Com relação aos casos que apresentaram encefalomalacia, a lesão foi mais freqüente no cerebelo (16/70; 22,8\%) (Fig.5) do que no tronco encefálico (10/70; $14,3 \%)$, medula espinhal $(7 / 54 ; 13,0 \%)$ e telencéfalo $(2 / 70 ; 2,8 \%)$. No tronco encefálico, a malacia estava distribuída principalmente na ponte $(6 / 70 ; 8,6 \%)$ e no diencéfalo $(5 / 70 ; 7,1 \%)$, e afetou menos freqüentemente o mesencéfalo (2/70; 2,8\%). Na medula espinhal, a malacia ocorreu principalmente no segmento C1-C5 (6/54; 11,1\%). Apenas um caso (1/70; $1,4 \%$ ) ocorreu fora desse segmento, esse caso afetou 0 segmento C6-T2. No telencéfalo, a malacia estava distribuída nos lobos frontal $(1 / 70 ; 1,4 \%)$, parietal $(1 / 70 ; 1,4 \%)$ e occipital $(1 / 70 ; 1,4 \%)$.
Necrose cortical laminar (NCL) evidenciada por neurônios com o citoplasma eosinofílico e encolhido e núcleo picnótico (neurônios vermelhos) ocorreu em 12 (17,1\%) casos. A distribuição dessa lesão foi a seguinte: hipocampo (10/70; 14,3\%) (Fig.6), lobos occipital (6/70; $8,6 \%)$, piriforme $(5 / 70 ; 7,1 \%)$, frontal $(4 / 70 ; 5,7 \%)$, parietal $(4 / 70[5,7 \%])$ e temporal (4/70 [5,7\%]). Em alguns casos em que ocorreu NCL também havia cromatólise central $(2 / 70 ; 2,8 \%)$, neuronofagia $(1 / 70 ; 1,4 \%)$ e perda neuronal $(1 / 70 ; 1,4 \%)$.

Astrogliose, caracterizada por hiperplasia e hipertrofia de astrócitos, ocorreu em 58 dos 70 casos (82,8\%). Essa lesão foi mais prevalente no cerebelo $(58 / 70 ; 82,8 \%)$ e telencéfalo $(56 / 70 ; 80,0 \%)$ do que no tronco encefálico (40/70; $57,1 \%)$ e medula espinhal $(25 / 54 ; 46,3 \%)$. Na grande maioria dos casos (52/70; $74,3 \%+20 / 54 ; 37,0 \%)$ havia astrócitos com características gemistocíticas e, em alguns desses casos (18/70;25,7\%), os gemistócitos eram multinucleados (sincícios de astrócitos) (Fig.7). No telencéfalo, astrogliose teve a seguinte distribuição: lobos frontal $(38 / 70 ; 54,3 \%)$, occipital $(29 / 70 ; 41,4 \%)$, parietal $(27 /$ 70 ; $38,6 \%)$, temporal $(22 / 70 ; 31,4 \%)$, piriforme (15/70; $21,4 \%)$ e hipocampo (15/70; 21,4\%). No tronco encefálico, astrogilose foi mais freqüente na ponte $(33 / 70 ; 47,1 \%)$ e no mesencéfalo (32/70; $45,7 \%$ ) do que no diencéfalo (24/70; 34,3\%).

Hipertrofia endotelial foi observada em 40 dos 70 casos $(57,1 \%)$. Em todos esses casos, as células endoteliais, preferencialmente dos vasos circundados por manguitos linfoplasmocitários, apresentavam citoplasma volumoso e núcleo grande formado por cromatina frouxamente agregada. Essa lesão foi vista principalmente no telencéfalo $(35 / 70 ; 50,0 \%)$ e menos freqüentemente no

Quadro 2. Prevalência dos principais achados histopatológicos no encéfalo e na medula espinhal de cães com cinomose de acordo com as diferentes faixas etárias

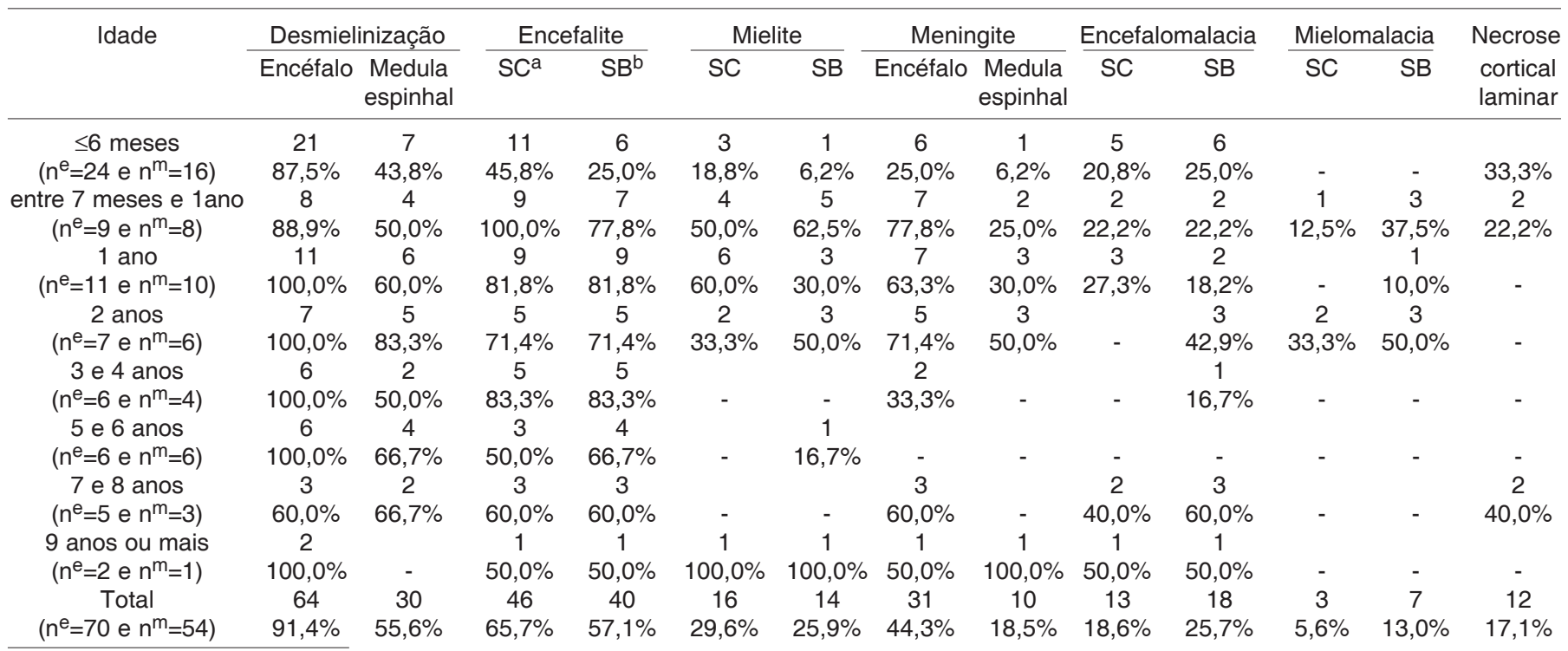

a SC = substância cinzenta; ${ }^{\mathrm{b}} \mathrm{SB}=$ substância branca; $\mathrm{n}^{\mathrm{e}}=$ número de casos em que o encéfalo foi examinado; $\mathrm{n}^{\mathrm{m}}=$ número de casos em que a medula espinhal foi examinada; - = alteração não descrita nessa faixa etária. 
tronco encefálico $(23 / 70 ; 32,8 \%)$, no cerebelo $(20 / 70$; $28,6 \%$ ) e na medula espinhal (12/70; $17,1 \%)$. No tronco encefálico, essa lesão afetou principalmente o diencéfalo $(18 / 70 ; 25,7 \%)$ e o mesencéfalo $(11 / 70 ; 15,7 \%)$, e foi menos comum na ponte $(5 / 70 ; 7,1 \%)$.

Esferóides axonais e câmaras de digestão foram observados principalmente na medula espinhal (12/54; $22,2 \%+10 / 54 ; 18,5 \%$, respectivamente), ocasionalmente no cerebelo $(7 / 70 ; 10,0 \%+3 / 70 ; 4,3 \%$, respectivamente) e raramente no tronco encefálico $(1 / 70 ; 1,4 \%)$.

Corpúsculos de Lentz ocorreram em astrócitos hipertróficos (58/70; 82,8\%) (Fig.8), neurônios (31/70; 44,3\%) (Fig.9), astrócitos gemistocíticos (22/70; 31,4\%), células do epêndima (16/70; 22,8\%) (Fig.10), células menigoteliais $(3 / 70 ; 4,3 \%)$ e em células epiteliais do plexo coróide (1/ $70 ; 1,4 \%)$. Esses corpúsculos ocorreram predominantemente no núcleo e ocasionalmente no citoplasma, nas seguintes proporções: astrócitos hipertróficos (56/70; $80,0 \%$ versus $2 / 70 ; 2,8 \%$ ), neurônios ( $28 / 70 ; 40,0 \%$ versus $3 / 70 ; 4,3 \%)$, astrócitos gemistocíticos (16/70; 22,8\% versus $6 / 70 ; 8,6 \%$ ) e células do epêndima (14/70; 20,0\% versus $2 / 70 ; 2,8 \%$ ). Nas células meningoteliais os corpúsculos de inclusão ocorreram apenas no núcleo. No

\section{Quadro 3. Distribuição da evolução das lesões de cino-} mose de acordo com a idade dos cães afetados

\begin{tabular}{|c|c|c|c|c|c|}
\hline Cão & Idade & Tipo de lesão & Cão & Idade & Tipo de lesão \\
\hline 1 & 2 meses & Subaguda & 36 & 1 ano & Crônica \\
\hline 2 & 2 meses & Subaguda & 37 & 1 ano & Subaguda \\
\hline 3 & 2 meses & Subaguda & 38 & 1 ano & Subaguda \\
\hline 4 & 3 meses & Crônica & 39 & 1 ano & Subaguda \\
\hline 5 & 3 meses & Aguda & 40 & 1 ano & Crônica \\
\hline 6 & 3 meses & Crônica & 41 & 1 ano & Subaguda \\
\hline 7 & 3 meses & Subaguda & 42 & 1 ano & Crônica \\
\hline 8 & 3 meses & Crônica & 43 & 1 ano & Crônica \\
\hline 9 & 4 meses & Subaguda & 44 & 1 ano & Crônica \\
\hline 10 & 4 meses & Aguda & 45 & 2 anos & Crônica \\
\hline 11 & 4 meses & Subaguda & 46 & 2 anos & Crônica \\
\hline 12 & 4 meses & Aguda & 47 & 2 anos & Crônica \\
\hline 13 & 4 meses & Subaguda & 48 & 2 anos & Crônica \\
\hline 14 & 4 meses & Aguda & 49 & 2 anos & Subaguda \\
\hline 15 & 5 meses & Crônica & 50 & 2 anos & Aguda \\
\hline 16 & 5 meses & Subaguda & 51 & 2 anos & Crônica \\
\hline 17 & 5 meses & Crônica & 52 & 3 anos & Subaguda \\
\hline 18 & 5 meses & Aguda & 53 & 4 anos & Crônica \\
\hline 19 & 6 meses & Crônica & 54 & 4 anos & Subaguda \\
\hline 20 & 6 meses & Subaguda & 55 & 4 anos & Subaguda \\
\hline 21 & 6 meses & Crônica & 56 & 4 anos & Aguda \\
\hline 22 & 6 meses & Aguda & 57 & 4 anos & Subaguda \\
\hline 23 & 6 meses & Subaguda & 58 & 5 anos & Subaguda \\
\hline 24 & 6 meses & Subaguda & 59 & 5 anos & Subaguda \\
\hline 25 & 8 meses & Subaguda & 60 & 5 anos & Subaguda \\
\hline 26 & 8 meses & Subaguda & 61 & 5 anos & Aguda \\
\hline 27 & 8 meses & Crônica & 62 & 5 anos & Aguda \\
\hline 28 & 8 meses & Subaguda & 63 & 6 anos & Subaguda \\
\hline 29 & 8 meses & Subaguda & 64 & 7 anos & Crônica \\
\hline 30 & 9 meses & Crônica & 65 & 7 anos & Subaguda \\
\hline 31 & 10 meses & Subaguda & 66 & 7 anos & Crônica \\
\hline 32 & 11 meses & Crônica & 67 & 7 anos & Aguda \\
\hline 33 & 11 meses & Aguda & 68 & 8 anos & Crônica \\
\hline 34 & 1 ano & Subaguda & 69 & 9 anos & Aguda \\
\hline 35 & 1 ano & Crônica & 70 & 13 anos & Crônica \\
\hline
\end{tabular}

epitélio do plexo coróide os corpúsculos de inclusão ocorreram no núcleo e no citoplasma. A prevalência dos principais achados histopatológicos de acordo com as diferentes faixas etárias estipuladas pode ser encontrada no Quadro 2. A distribuição completa da evolução das lesões de acordo com a idade dos cães pode ser vista no Quadro 3.

\section{DISCUSSÃO}

Nos 70 cães deste estudo a idade variou entre dois meses e 13 anos; em quase metade (33; 47,1\%) dos casos os cães tinham até um ano de idade e em cerca de um terço $(24 ; 34,3 \%)$ dos casos os cães tinham até seis meses de idade. Trinta casos (42,8\%) ocorreram em cães que tinham entre um e seis anos de idade; apenas sete $(10,0 \%)$ casos ocorreram em cães com sete anos de idade ou mais. Esses resultados demonstram que filhotes (cães até um ano de idade) e adultos (cães com idade entre um e seis anos) são as faixas etárias mais acometidas, e embora a doença tenha sido mais prevalente em filhotes, esses foram apenas um pouco mais afetados do que os adultos. Esses resultados são semelhantes aos de um estudo norte-americano (Tipold et al. 1992) que compilou dados de mais de 100 casos de cinomose com manifestação neurológica, observando que pouco mais da metade dos casos ocorreram em cães com até um ano de idade, aproximadamente um terço desses cães tinham menos de quatro meses de idade e que boa parte dos casos ocorreu em cães adultos.

Segundo alguns autores (Krakowka \& Kostner 1976), um dos fatores que contribui para a maior prevalência de cinomose em filhotes está relacionado com a imaturidade do sistema imunológico que favorece uma maior susceptibilidade à infecção pelo VCC. Outros fatores incluem uma associação de ausência de vacinação, exposição de fiIhotes não-vacinados ao vírus após a perda da imunidade materna e concentração insuficiente de anticorpos maternos transmitida aos filhotes (Greene \& Appel 2006). É possível que a alta prevalência de cinomose em cães adultos deste estudo, seja devida à falta de revacinação periódica, um procedimento ainda pouco freqüente entre proprietários de cães no Brasil.

Lesões macroscópicas no SNC de cães com cinomose têm sido descritas na literatura (Perdrau \& Pugh 1930, King 1939, Maclntyre et al. 1948, Trevan 1952, Fischer 1965, Summers et al. 1995, Greene \& Appel 2006) e alguns autores (Summers et al. 1995) afirmam que elas ocorrem com certa freqüência, entretanto, sua prevalência é desconhecida. Neste estudo, a prevalência das lesões macroscópicas no encéfalo e na medula espinhal foi baixa $(7,1 \%$ e $3,7 \%$, respectivamente). Tanto no encéfalo quanto na medula espinhal, em apenas 1,4\% e 3,7\% dos casos, respectivamente, a lesão macroscópica correspondia a malacia. Nesse ponto, cabe ressaltar que em $31,4 \%$ e $13,0 \%$ casos havia malacia no exame histopatológico do encéfalo e da medula espinhal, respectivamente. Acreditamos que, pelo menos em parte, essa bai- 
xa prevalência possa ser atribuída ao fato do exame macroscópico da superfície de corte transversal do SNC ter sido realizada após a fixação do encéfalo e da medula espinhal em formol por um período superior a quatro dias, o que resulta em alteração da cor do tecido e pode dificultar a visualização de eventuais lesões macroscópicas. Além disso, outro fator que pode ter contribuído para dificultar a visualização macroscópica da malacia nesses casos foi a ausência de hemorragia, já que lesões hemorrágicas, como as que são vistas em associação com outros tipos de encefalite em várias espécies animais, são mais facilmente perceptíveis ao exame macroscópico (Innes \& Saunders 1962).

Com relação à distribuição das lesões de cinomose no SNC, todas as regiões anatômicas examinadas do encéfalo (cerebelo, ponte, mesencéfalo, diencéfalo, hipocampo e lobos frontal, parietal, temporal, piriforme e occipital) e da medula espinhal (cervical cranial [C1-C5], cervicotorácica [C6-T2], toracolombar [T3-L3] e lombossacra [L4-S3]) apresentaram lesão, o que confirma o caráter multifocal da cinomose, um aspecto evidenciado desde os primeiros estudos histopatológicos acerca dessa doença (Perdrau \& Pugh 1930, Hurst et al. 1943, Maclntyre et al. 1948, Innes 1949, Koprowski et al. 1950, Trevan 1952, Ribelin 1953, Lauder et al. 1954, Gillespie \& Rickard 1956). Entretanto, independentemente do tipo de lesão, o encéfalo foi afetado aproximadamente 1,4 vezes mais do que a medula espinhal $(91,4 \%$ versus $66,7 \%)$, demonstrando que embora cinomose seja considerada uma doença que cursa com lesão multifocal no SNC, a maior parte das lesões ocorre no encéfalo. Esse achado talvez possa ser atribuído à penetração do vírus através do líquido cefalorraquidiano com subseqüente lesão nas áreas próximas ao quarto ventrículo, uma forma de neuroinvasão sustentado por vários autores (Higgins et al. 1982, Vandevelde et al. 1985, Vandevelde \& Zurbriggeb 1995, Vandevelde \& Zurbriggeb 2005, Beineke et al. 2009).

Considerando as lesões histológicas do SNC de um modo geral, a prevalência do comprometimento de cada região anatômica nos 70 casos deste estudo, em ordem decrescente de freqüência, foi: cerebelo, diencéfalo, lobo frontal, ponte, mesencéfalo, medula espinhal C1-C5, lobo occipital, lobo parietal, medula espinhal L4-S3, medula espinhal T3-L3, lobo temporal, hipocampo, medula espinhal C6-T2 e lobo piriforme. O conhecimento da freqüência com que as lesões de cinomose afetam as diferentes regiões do SNC é importante principalmente nos casos em que o patologista não dispõe de informações do exame neurológico. Assim, sabendo-se que as lesões ocorrem no cerebelo, diencéfalo, lobo frontal, ponte e mesencéfalo em $70 \%-90 \%$ dos casos, essas cinco estruturas podem ser consideradas as regiões de escolha para o exame histopatológico, principalmente naquelas situações em que o histórico clínico é incompleto ou inexistente. No entanto, essa é uma informação válida somente em situações de diagnóstico nas quais o patologista não dispõe de tempo suficiente ou possui recursos financeiros limitados que inviabilizam o exame de todas as 14 secções do SNC aqui descritas, pois não é aconselhável examinar habitualmente apenas uma ou outra dessas áreas.

Com relação ao tipo de lesão que ocorreu no encéfalo, desmielinização foi a mais freqüente, sendo observada em mais de $91,4 \%$ dos casos. Em um estudo retrospectivo sobre a prevalência das lesões histológicas encefálicas, desmielinização ocorreu em $89,4 \%$ dos casos (Silva et al. 2007), uma prevalência praticamente idêntica à observada neste estudo. A comparação entre esses dados indica que a desmielinização é uma lesão bastante constante, o que pode ser atribuído ao fato de o cerebelo, local onde a desmielinização ocorreu mais freqüentemente, ter sido a principal região anatômica examinada nos casos desse estudo retrospectivo (Silva et al. 2007).

Considerando a distribuição da desmielinização, houve marcada variação entre as regiões anatômicas avaliadas. A alta prevalência da desmielinização no cerebelo $(88,6 \%)$ e tronco encefálico $(77,1 \%)$, principalmente na ponte $(65,7 \%)$ e no diencéfalo $(61,4 \%)$ é relativamente semelhante à observada em outros estudos (Innes \& Saunders 1962, Vandevelde et al. 1981, Vandevelde et al. 1982a,b, Greene \& Appel 2006). Além disso, neste estudo pode-se determinar que das cinco regiões (folhas do cerebelo, substância medular do cerebelo, teto do quarto ventrículo, segmento $\mathrm{C} 1-\mathrm{C} 5$ da medula espinhal e tegmento mesencefálico) mais afetadas pela desmielinização, três fazem parte do cerebelo.

Neste estudo, algum tipo de inflamação no encéfalo ocorreu em $72,8 \%$ dos casos de cinomose. Nesses casos, a inflamação ocorreu principalmente no parênquima $(70 \%)$, e leptomeningite foi menos freqüentemente observada $(44,3 \%)$, ao contrário do que afirmam alguns autores (Ribelin 1953, Innes \& Saunders 1962), que consideram a meningite uma lesão constante na cinomose. Essa prevalência da inflamação no encéfalo é maior do que a previamente descrita $(56,0 \%)$ em um estudo retrospectivo por nós realizado (Silva et al. 2007) e isso possivelmente deva-se à menor quantidade de regiões anatômicas avaliadas, que na grande maioria das vezes incluía apenas o cerebelo e o lobo frontal.

A inflamação é um aspecto histopatológico classificatório da evolução da doença. Casos de cinomose com inflamação constituída de infiltrado mononuclear perivascular e leptomeníngeo são classificados como subagudos ou crônicos. Na doença subaguda, a desmielinização é mais intensa do que na fase aguda e é acompanhada de inflamação leve, mas não ocorre malacia. Na doença crônica, a desmielinização e a inflamação aumentam em intensidade e freqüentemente há malacia. O conceito corrente de que cães jovens apresentam lesões predominantemente agudas (Fenner 2004, Summers et al. 1995), não pôde ser confirmado por este estudo, pois a maioria dos filhotes (cães com menos de um ano de idade) por nós examinados apresentou mais freqüentemente lesões interpretadas como subagudas $(48,5 \%)$ ou crônicas 
$(30,3 \%)$ do que agudas $(21,2 \%)$. Com base nesses aspectos, concluímos que é impreciso inferir as lesões da cinomose com base apenas na idade dos cães. Além disso, se compararmos os casos com lesões interpretadas como agudas entre filhotes e cães mais velhos (cães com sete anos de idade ou mais), a prevalência de lesão aguda nos cães com mais idade foi maior $(28,6 \%)$ do que nos filhotes $(21,2 \%)$, demonstrando que, pelo menos no que se refere à evolução da doença, não há qualquer relação entre a idade e o desenvolvimento temporal da lesão.

Em relação às síndromes clínicas, dentre os 70 casos deste estudo, independentemente da idade do cão, todos apresentavam critérios histopatológicos que Ihes enquadrariam dentro da forma clássica da encefalomielite da cinomose, que inclui as chamadas encefalomielopatia desmielinizante e encefalomielite multifocal progressiva crônica. Nenhum dos casos aqui descritos pôde ser incluído em qualquer outra forma já descrita da doença, como: encefalite pós-vacinal, encefalite dos cães velhos, encefalite crônica recidivante dos cães adultos e polioencefalite do corpúsculo de inclusão.

Casos de cinomose com NCL são raramente relatados (Lisiak \& Vandevelde 1979, Braund et al. 1981, Finnie \& Hooper 1984, Silva et al. 2007), no entanto, neste estudo, NCL ocorreu em $17,1 \%$ dos casos, ou seja, uma prevalência cerca de seis vezes maior do que a previamente descrita $(2,6 \%)$ em um estudo retrospectivo por nós realizado (Silva et al. 2007). Essa relativamente alta prevalência de NCL pode ser atribuída a dois fatores: (1) NCL ocorre com uma freqüência um pouco maior do que é descrita na maior parte dos estudos, mas o hábito incomum de examinar o hipocampo (local onde a NCL foi mais freqüente neste estudo) pode diminuir as chances de observar a lesão em um maior número de casos; (2) NCL talvez tenha surgido com mais intensidade nos últimos anos devido à circulação de cepas neurotrópicas mais virulentas e que produzem mais lesão na substância cinzenta.

Nos casos de NCL observados neste estudo, alterações vasculares proliferativas foram bastante freqüentes na substância cinzenta telencefálica. No entanto, não foi possível determinar se além de hipertrofia havia também hiperplasia endotelial, embora muitas vezes a impressão fosse de verdadeira neovascularização, como alguns autores (Innes \& Saunders 1962, Fischer 1965) sugerem que ocorra nesses casos. Afora os casos com NCL, em que necrose não-laminar de neurônios corticais e de neurônios dos núcleos também foi observada com alguma freqüência, necrose e degeneração neuronal não foi uma lesão comum, mesmo naqueles casos em que havia corpúsculos de inclusão em neurônios do córtex; nesses casos os neurônios tinham aparência normal à microscopia de luz, embora se saiba pela literatura (Summers et al. 1995) que ocorrem várias alterações ultra-estruturais detectáveis sob microscopia eletrônica.

À semelhança do que é descrito na literatura (Summers \& Appel 1994, Greene \& Appel 2006, Silva et al. 2007), corpúsculos de inclusão foram observados em astrócitos (geralmente naqueles hipertróficos) na maioria dos casos $(82,8 \%)$, basicamente no núcleo. Corpúsculos de inclusão também foram freqüentes $(44,3 \%$ ) em neurônios, uma prevalência cerca de 12 vezes maior do que a previamente descrita $(3,5 \%)$ em um estudo retrospectivo por nós realizado (Silva et al. 2007). Acreditamos que essa marcante diferente se deva a alta prevalência de corpúsculos de inclusão em astrócitos, que na maioria das vezes são prontamente identificados, fornecendo dados suficientes para fechar o diagnóstico e tornando a procura por corpúsculos de inclusão em neurônios desnecessária.

Dentre os 70 casos deste estudo, astrogliose (hiperplasia e hipertrofia de astrócitos) foi uma lesão constante, observada em mais de $80 \%$ dos casos, muitas vezes com gemistócitos e formação sincícios. Além de sincícios de astrócitos, incomumente também foram observados sincícios de células do epêndima, sincícios de células meningoteliais e, raramente, sincícios de células gitter. A capacidade de induzir sincícios celulares é uma característica dos paramixovírus (Summers \& Appel 1985) e a observação de sincícios pode servir como auxílio para o diagnóstico de cinomose em situações em que os corpúsculos de inclusão não são prontamente identificados. Além da cinomose, apenas a infecção pelo vírus da parainfluenza canina tipo 1 (VPC), também pertence à família Paramyxoviridae, induz sincícios celulares, mas isso não seria causa para confusão no diagnóstico, pois casos de encefalite pelo VPC são muito raros em cães (Arns et al. 2007).

\section{CONCLUSÕES}

Os resultados deste estudo permitem concluir que: (1) encefalomielite induzida pelo VCC é mais prevalente em filhotes e adultos; (2) lesões macroscópicas no SNC ocorrem com baixa freqüência; (3) o encéfalo é mais acometido do que a medula espinhal; (4) as cinco regiões anatômicas mais afetadas do encéfalo são, em ordem decrescente de freqüência, o cerebelo, o diencéfalo, o lobo frontal, a ponte e o mesencéfalo; (5) a região anatômica mais afetada da medula espinhal é o segmento cervical cranial (C1-C5); (6) lesões subagudas e crônicas são mais comuns do que lesões agudas; (7) desmielinização é a lesão mais prevalente e ocorre principalmente no cerebelo, na ponte e no diencéfalo, quase sempre acompanhada de astrogliose e inflamação não-supurativa; (8) na maior parte dos casos em que há astrogliose, observam-se astrócitos gemistocíticos, freqüentemente com formação de sincícios; (9) leptomeningite não-supurativa, malacia e necrose cortical laminar são lesões relativamente freqüentes no encéfalo, mas não na medula espinhal; (10) corpúsculos de inclusão no encéfalo são muito comuns, ocorrem principalmente em astrócitos e com freqüência menor em neurônios; no entanto, independentemente da célula afetada, são vistos predominantemente no núcleo; (11) uma classificação da encefalite na cinomose com base em síndromes clínicas relacionadas com a idade do cão é imprecisa. 


\section{REFERÊNCIAS}

Amude A.M., Alfieri A.A. \& Alfieri A.F. 2006. Clinicopathological findings in dogs with distemper encephalomyelitis without characteristic signs of the diseases. Res. Vet. Sci. 82:416-422.

Appel M.J.G. \& Summers B.A. 1995. Pathogenicity of morbilliviruses for terrestrial carnivores. Vet. Microbiol. 44:187-191.

Appel M.J.G. 1969. Pathogenesis of canine distemper. Am. J. Vet. Res. 30:1167-1182.

Arns C.W., Spilki F.R. \& Almeida R.S. 2007. Paramyxoviridae, p.659688. In: Flores E.F. (Ed.), Virologia Veterinária. UFSM, Santa Maria. 888p.

Beineke A., Puff C., Seehusen F. \& Baumgärtner W. 2009. Pathogenesis and immunopathology of systemic and nervous canine distemper. Vet. Immunol. Immunopathol. 127:1-18.

Braund K.G., Crayley R.R. \& Speakmen C. 1981. Hippocampal necrosis associated with canine distemper virus infection. Vet. Rec. 109:122123.

Caswell J.L. \& Williams K.J. 2007. Respiratory system, p.523-653. In: Maxie M.G. (Ed.), Pathology of Domestic Animals. Vol.2. $5^{\text {th }}$ ed. Saunders Elsevier, Philadelphia. 771p.

Chappuis G. 1995. Control of canine distemper. Vet. Microbiol. 4:351358.

Chrisman C.L. 1985. Neurologia dos Pequenos Animais. Roca, São Paulo. 432p.

Fenner W.R. 2004. Doenças do cérebro, p.586-638. In: Ettinger S.J. \& Feldman E.C. (Eds), Tratado de Medicina Interna Veterinária: doenças do cão e do gato. Vol.1. 4ª ed. Guanabara Koogan, Rio de Janeiro. 1038 p.

Fighera R.A., Souza T.M., Silva M.C., Brum J.S., Graça D.L., Kommers G.D., Irigoyen L.F. \& Barros C.S.L. 2008. Causas de morte e razões para eutanásia de cães da Mesorregião do Centro Ocidental RioGrandense (1964-2004). Pesq. Vet. Bras. 28:223-230.

Fischer K. 1965. Einschlusskörperchen bei Hunden mit StaupeEnzephalitis und anderen Erkrankungen des Zentralnervensystems. Pathol. Vet. 2:280-410.

Gillespie J.H. \& Rickard C.G. 1956. Encephalitis in dogs produced by distemper virus. Am. J. Vet. Res. 17:103-108

Gillespie J.H. 1962. The virus of canine distemper. Ann. N.Y. Acad. Sci. 30:540-547.

Greene C.E. \& Appel M.J. 2006. Canine distemper, p.25-41. In: Greene C.E. (Ed.), Infectious Diseases of the Dog and Cat. $3^{\text {th }}$ ed. Saunders Elsevier, St Louis. 1387p.

Higgins R.J., Krakowka S.G., Metzler A.E. \& Koestmer A. 1982. Primary demyelination in experimental canine distemper virus induced encephalomyelitis in gnotobiotic dogs: Sequencial immunological and morphologic findings. Acta Neuropathol. 58:1-8.

Hurst E.W., Cooke B.T. \& Melvin P. 1943. Nervous distemper in dogs. Aust. J. Exp. Biol. Med. Sci. 21:115-126.

Innes J.R.M. \& Saunders L.Z. 1962. Viral and rickettsial encephalomyelitides, p.337-450. In: Innes J.R.M. \& Saunders L.Z. (Eds), Comparative Neuropathology. Academic Press, New York. 839p.

Innes J.R.M. 1949. The relation of distemper infection to the aethiology of canine encephalopathies. Vet. Rec. 61:73-77.

King L.S. 1939. Disseminated encephalomyelitis of the dog. Arch. Pathol. 8:51-162.

Koprowski G.A., Jervis G.A., James T.R., Burkhart R.L. \& Poppensiek G.C. 1950. A study of canine encephalitis. Am. J. Hyg. 51: 63-75.
Koutinas A.F., Polizopoulou Z.S., Baumgäertner W., Lekkas S. \& Kontos V. 2002. Relation of clinical to pathological changes in 19 cases of canine distemper encephalomyelitis. J. Comp. Pathol. 126:47-56.

Krakowka S. \& Koestner A. 1976. Age-related susceptibility to infection with canine distemper virus in gnotobiotic dogs. J. Infect. Dis. 134:629632.

Lauder I.M., Martin W.B., Gordon E.B., Lawson D.D., Campbell R.S.F. \& Watrach A.M. 1954. Survey of canine distemper. Vet. Rec. 66:623632.

Macintyre A.B., Trevan D.J. \& Montgomerie R.F. 1948. Observations on canine encephalitis. Vet. Rec. 60:635-648.

Maxie M.G. \& Youssef S. 2007. Nervous system, p.281-457. In: Maxie M.G. (Ed.), Pathology of Domestic Animals. Vol.1. $5^{\text {th }}$ ed. Saunders Elsevier, Philadelphia. 899p.

Moll P., Alldinger S., Baumgärtner W. \& Adami M. 1995. Distemper in wild carnivores: An epidemiological, histological and immunocytochemical study. Vet. Microbiol. 44:193-199.

Perdrau J.R. \& Pugh L.P. 1930. The pathology of disseminated encephalomyelitis of the dog (The "nervous form of canine distemper"). J. Pathol. 33:79-91.

Ribelin W.E. 1953. The incidence of distemper in canine encephalitis cases. Am. J. Vet. Res. 14:96-104.

Silva M.C., Fighera R.A., Brum J.S., Graça D.L., Kommers G.D., Irigoyen L.F. \& Barros C.S.L. 2007. Aspectos clinicopatológicos de 620 casos neurológicos de cinomose em cães. Pesq. Vet. Bras. 27:215-220.

Summers B.A. \& Appel M.J.G. 1985. Syncytia formation: An aid in the diagnosis of canine distemper encephalomyelitis. J. Comp. Pathol. 95:425-435.

Summers B.A. \& Appel M.J.G. 1994. Aspects of canine distemper virus and measles virus encephalomyelitis. Neuropathol. Appl. Neurobiol. 20:525-534.

Summers B.A., Cummings J.F. \& De Lahunta A. 1995. Veterinary Neuropathology. Mosby, St Louis. 527p.

Thomas W.B., Sorjonem D.C. \& Steiss J.E. 1993. A retrospective evaluation of 38 cases of canine distemper encephalomyelitis. J. Am. Anim. Hosp. Assoc. 29:129-133.

Tipold A., Vandevelde M. \& Jaggy A. 1992. Neurological maninfestations of canine distemper virus infection. J. Small Anim. Pract. 33:466-470.

Trevan D.J. 1952. On canine encephalitis. Proc. First International Congress of Neuropathology, Beckenham, UK, p.198-210.

Vandevelde M. \& Zurbriggen A. 1995. The neurobiology of canine distemper virus infection. Vet. Microbiol. 44:271-280.

Vandevelde M., Fankhauser R., Kristensen F. \& Kristensen B. 1981. Immunoglobulins in demyelinating lesions in canine distemper encephalitis. An immunohistological study. Acta Neuropathol. 54:3141.

Vandevelde M., Higgins R.J., Kristensen B., Kristensen F., Steck A.J. \& Kihn U. 1982a. Demyelinating in experimental canine distemper virus infection: Immunological, pathological, and immunohistological studies. Acta Neuropathol. 56:285-293.

Vandevelde M., Kristensen F., Kristensen B., Steck A.J. \& Kihn U. 1982b. Immunological and pathological findings in demyelinating encephalitis associated with canine distemper virus. Acta Neuropathol. 56:1-8.

Vandevelde M., Zurbriggen A., Higgins R.J. \& Palmer D. 1985. Spread and distribution of viral antigen in nervous canine distemper. Acta Neuropathol. 67:211-218.

Vandevelde M. \& Zurbriggen A. 2005. Demyelination in canine distemper vírus infection: A review. Acta Neuropathol. 109:56-68. 